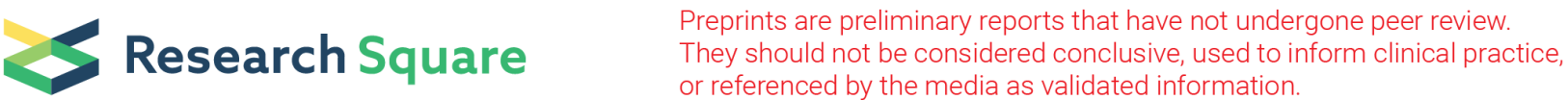

\section{Concomitant Laparoscopic Hiatal Hernia Repair With Cholecystectomy: A Multicentric Study}

paul zarogoulidis ( $\sim$ pzarog@hotmail.com )

https://orcid.org/0000-0001-5119-2207

\section{Silviu-Daniel Preda}

Universitatea din Craiova Facultatea de Economie si Admistrarea Afacerilor

\section{Sapalidis Konstantinos}

Aristotle University of Thessaloniki School of Medicine

Vasile Virgil Binţintan

Universitatea de Medicine si Farmacie din Craiova Facultatea de Medicina

\section{Daniel Alin Cristian}

Universitatea de Medicine si Farmacie din Craiova Facultatea de Medicina

\section{Marius Bică}

Universitatea de Medicine si Farmacie din Craiova Facultatea de Medicina

\section{Ştefan Pătrașcu}

Universitatea de Medicine si Farmacie din Craiova Facultatea de Medicina

\section{Stelian Pantea}

Universitatea de Medicine si Farmacie din Craiova Facultatea de Medicina

\section{Daniela Patru}

Universitatea de Medicine si Farmacie din Craiova Facultatea de Medicina

\section{Marin Valeriu Şurlin}

Universitatea de Medicine si Farmacie din Craiova Facultatea de Medicina

\section{Research}

Keywords: hernia, laparoscopic, Toupet, Dorr, Floppy-Nissen, Fundopexy.

Posted Date: June 11th, 2020

DOI: https://doi.org/10.21203/rs.3.rs-34194/v1

License: (c) (i) This work is licensed under a Creative Commons Attribution 4.0 International License.

Read Full License 


\section{Abstract}

Introduction

Concomitant surgery refers to performing two or more surgical operations on one patient under the same anesthesia.

\section{Patients and Methods}

We performed a retrospective multicentric study from October 2016 to October 2019, analyzing patients who underwent laparoscopic hiatal hernia repair. We extracted data of patients who underwent concomitant laparoscopic surgery for both hiatal hernia repair and cholecystectomy in the following Clinics: 1st Clinic of Surgery of Craiova Emergency Clinical County Hospital, "Colțea" Hospital, 3rd Clinic of Surgery of Cluj-Napoca and 3rd Surgery Clinic of University General Hospital of Thessaloniki and identified 20 patients who underwent hiatal hernia repair and had an added cholecystectomy. Allocation of data by hiatal hernia type showed 6 type IV hernia (complex hernia), 13 type III hernias (mixed type) and 1 type I hernia (sliding hernia). Out of the 20 cases analyzed, 19 were chronic cholecystitis and one patient presented with acute cholecystitis.Average operating time was 168 minutes. Blood loss was minimum. Cruroraphy was performed in all cases, mesh reinforce was added in 5 cases, and fundoplication was added in all cases: 3 Toupet, 2 Dorr and 15 Floppy-Nissen. Fundopexy was routinely added in cases with Toupet fundoplication. Cholecystectomy was performed in the following manner: 19 retrograde, 1 bipolar.

Results

All patients had favorable postoperative evolution. Patient follow up was at 1 month, 3 months and 6 months, with no sign of recurrence for hiatal hernia (anatomical or symptomatic) and no postcholecystectomy syndrome.

In conclusion

concomitant laparoscopic hiatal hernia repair and cholecystectomy is a safe and feasible option for patients with indication of surgery for both pathologies.

\section{Introduction}

Laparoscopic surgery is the golden standard for both hiatal hernia repair and cholecystectomy and offers fast recovery time with less operative time and is both safe and effective.[1] Type I hiatal hernias with impact on quality of life and refractive to medication, type II, III and IV symptomatic hiatal hernia have indication for surgery.[2] Concomitant surgery refers to performing two or more surgical operations on one patient under the same anesthesia. With the quick and widespread adoption of laparoscopic approach in surgery, the emergence of concomitant surgery has seen a rapid incline in the number of cases. It has been almost three decades since laparoscopic approach has become the gold standard for 
cholecystectomy [3] and the standard for hiatal hernia repair today is also by laparoscopic approach.[2] Laparoscopy is not the standard for all surgical interventions, but considering that the minimally invasive approach for both hiatus hernia and cholecystectomy is the standard of care, concomitant surgery has its charm. The idea that you can combine multiple minimally invasive surgeries and perform them under one anesthesia is very appealing, as in open surgery, plus the advantages of minimal invasivity: decrease in postoperative stay, decrease in analgesic use, early recovery (when compared to procedures performed at different times), and increase in patient satisfaction. However we should take into account the prolongation of operative time, risk for both intraoperative complications and postoperative morbidities for both interventions.[4]

\section{Materials And Methods}

We performed a retrospective multicentric study from October 2016 to October 2019, analyzing patients who underwent laparoscopic hiatal hernia repair. We extrapolated data of patients who underwent concomitant laparoscopic surgery for both hiatal hernia repair and cholecystectomy in the following Clinics: 1st Clinic of Surgery of Craiova Emergency Clinical County Hospital, "Colțea" Hospital, 3rd Clinic of Surgery of Cluj-Napoca and $3^{\text {rd }}$ Surgery Clinic of University General Hospital of Thessaloniki. We collected data regarding demographics, comorbidities, imagistic, operative time, blood loss, intraoperative complications, postoperative evolution and follow-up. Values were imported into Microsoft Excel (Microsoft Office) and analyzed. Patients presented indication for surgery for both hiatal hernia repair and cholecystectomy. In this study, no patient with completely asymptomatic gallbladder lithiasis was included. For the diagnosis of hiatal hernia one or more of the following were performed: upper digestive endoscopy, oral and intravenous contrast enhanced computed tomography and upper digestive endoscopy. Preoperative Visick score for reflux disease was at least three. Gallbladder lithiasis was diagnosed with abdominal ultrasound. Preoperative, all patients underwent deep venous thrombosis (DVT) and pulmonary embolism (PE) prophylaxis with low molecular weight heparin, bowel preparation with anti-foaming agents to reduce bloating and nil per os at least 12 hours before surgery. Interventions were performed under general anesthesia, with endotracheal intubation for all patients. All patients were placed in Trendelenburg French position, both arms tucked along the upper body.

\section{Results}

We identified 20 patients who underwent laparoscopic hiatal hernia repair and cholecystectomy in the same operative time. Mean age was 63 years-old, median of 65 years, minimum of 46 years old, maximum of 75 years old and standard deviation was 7.2 years. All patients were female, and one out of 20 patients was admitted through emergency setting, while the rest were elective. Case distribution by age group is shown in Fig. 1. Four patients (20\%) were from a rural area, while 16 patients (80\%) were from an urban area. Allocation of data by hiatal hernia type showed 6 type IV hernia (complex hernia), 13 type III hernias (mixed type) and 1 type I hernias (sliding hernia) (Fig. 2). Out of the 20 cases analyzed, 19 were chronic cholecystitis and one patient presented with acute cholecystitis (Fig. 3). The most frequent 
comorbidities were obesity (10 patients) and hypertension (17 patients). Most frequent symptom was heartburn, present in $18 / 20$ patients $(90 \%)$ with a symptom duration ranging from 1 year to 20 years, under proton pump inhibitor medication, with partial symptom cessation. Regurgitations were present in 13 patients, the average duration of symptoms was 1 year. Pain was the second most prevalent symptom and if ordered by location frequency it was: epigastric (50\%); left hypochondrium (33.3\%), left hemithorax (25\%) and retrosternal pain (16.66\%). Pain was postprandial in 9 patients (45\%), while lying down in 7 patients (35\%), ceased after eructation in 4 patients $(20 \%)$ and referred pain in the left shoulder in 4 patients (20\%). Other presenting symptoms with a lower incidence were: dysphagia 4 cases, anemia 5 cases, coughing 5 cases (Fig. 4). The performed imaging, by order of frequency were: upper digestive endoscopy (85\%), barium meal (60\%) and computed tomography (20\%) (Fig. 5).Insufflation by Veress needle in 17 cases, 3 cases with optical access; insufflation point: 14 supra-umbilical, 6 Palmer point, with no insufflation incidents. Average operating time was 168 minutes, median 180 minutes, minimum 120 minutes, and maximum 210 minutes. Blood loss was minimum. Cruroraphy was performed in all cases, mesh reinforce was added in 5 cases, and fundoplication was added in all cases: 3 Toupet, 2 Dorr and 15 Floppy-Nissen. Short gastric vessels of the fundus were divided in all cases, for better mobilization. Wrap height varied between 2-3 centimeters. Fundopexy was routinely added in cases with Toupet fundoplication. Cholecystectomy was performed in the following manner: 19 retrograde, 1 bipolar. Drainage for gallbladder was added in 16 cases and was kept in place for 1-5 days. Nasogastric aspiration tube was not maintained in the postoperative period. Three patients stayed overnight in the intensive care unit. All patients had favorable postoperative course, started active mobilization by postoperative day 1 , passage of flatus by postoperative day 2 and had a stool emission by discharge. Postoperative discharge was between POD 3 and POD 9, average of 5.5 days, median 6 days. Opioid analgesics were used only during anesthesia, broad spectrum intravenous antibiotic was given intraoperatively for all patients at anesthesia induction and only one patient with acute cholecystitis received broad spectrum intravenous antibiotic 4 days. Postoperative pain management was achieved by non-opioid analgesia on demand of the patient. Pain was measured preoperative, postoperative and at 1month follow-up using the Pain visual analogue scale (VAS) preoperative (Fig. 6). Patient follow up was at 1 month, 3 months and 6 months, with no sign of recurrence for hiatal hernia (anatomical or symptomatic) and no minor complaints of postcholecystectomy syndrome, like fullness or dullness in the upper right quadrant, especially after some movements

\section{Discussion}

With the increase in safety and experience of laparoscopic surgery, the desire to perform more than one operation under one anesthesia has risen in order to take advantage of the benefits of minimally invasive surgery. $[4,5]$ Performing both hiatal hernia repair and cholecystectomy through laparoscopic approach is feasible and safe, and by performing both surgeries under one anesthesia the need for a second hospitalization is erased, quality of life is improved, patient has no need to take multiple work breaks.[6] The combined procedure needs no supplementary trocar insertion other than that for hiatal hernia repair, as trocar positioning resembles the French technique for cholecystectomy. An experienced surgeon who 
regularly performs hiatal hernia repair should meet no impediment in combining both surgeries, even in the presence of comorbidities such as obesity. The decision to perform this combined surgery must stem from the indications for surgery for both pathologies. Trocar insertion must be planned beforehand, with ergonomy and triangulation for laparoscopic knot tying and suturing kept in mind. In morbidly obese patients, we must bear in mind that the umbilicus is not a reliable landmark and positioning of the landmark should be at 15 centimeters from the xiphoid on the xipho-umbilical line.[7] Imaging plays a paramount role and should not be discredited by the desire to reduce costs, as the importance of the findings can play a vital role in the indication for surgery, procedure used and planning. Upper digestive endoscopy, the most performed investigation in our study for hiatus hernia can not only diagnose hiatal hernia but also esophagitis, Cameron ulcers and other benign or malign coexisting pathologies and can lead to a decision for surgery. Upper digestive endoscopy, in the hands of an experienced endoscopist can even rise the suspicion of a parahiatal hernia which can be confirmed by barium meal.[8] Barium meal is the gold standard for diagnosing hiatus hernia and it brings the benefit of excellent visualization of hernia sac and provides orientation for the surgeon. It was not the most performed investigation in our study, as we believe that if endoscopy provides large sizes of the hernia (large enough to classify it as a type 3), or if a type 2 paraesophageal hernia is present, barium meal is no longer needed. Barium meal offers a very good visual representation of the herniated stomach, but is lacking in cases of complex hernias in which other abdominal organs are herniated. Computed tomography (CT) should not be overlooked as it has the potential to provide the most information, especially if enhanced with intravenous and oral contrast. It can diagnose both gallbladder stones, choledocholithiasis and all types of hiatus hernia; it can provide a better understanding of the particular anatomy of every patient. With the emergence of tridimensional reconstruction software and preoperative planning software, CT can bring a vital role in surgical planning of trocar positioning for better ergonomy for the surgeon, decreased blood loss and operating time. Performing both surgeries provides the evident benefit of one anesthesia and one surgical time for two pathologies and is both safe and feasible in the hands of an experienced laparoscopic team.[4] Operating time was 168 minutes compared to the average operating time of the standalone hiatal hernia repairs, which was 148 minutes. Operating time is similar with standalone surgery and blood loss was minimum in both cases. Oral intake, bowel movement and active mobility resumption was similar with standalone hiatal hernia surgery. Although no mesh hiatoplasty or mesh reinforce was performed we are not against use of mesh in the hiatus, but we are against routine use of mesh. However, although evidence exists regarding safety in placing mesh in clean-contaminated cases[9-14], we believe that the current level of evidence is not high enough and we advise use of mesh only in carefully selected cases if cholecystectomy is performed. We must not forget the dreaded complications meshes can produce and we believe that it should only be used as a last resort, in cases where crural appropriation is not possible or in selected cases of recurrent hiatal hernia. Regarding the order of the interventions, the hiatal hernia is usually performed first and then the cholecystectomy. For surgeons who regularly operate between the patients legs, the transition is easy, but for surgeons who perform hiatal hernia repair from the right side of the patient, the transition is more difficult, having to change the position of the laparoscope. Common bile duct injuries are the Achilles heel in laparoscopic surgery versus open surgery with reported rates being higher in the laparoscopic group.[14-20] Although 
laparoscopic cholecystectomy is a relatively common and simple procedure, the surgeon is performing it after a hiatal hernia repair, which can lead to fatigue. The surgeon should be in a familiar position for cholecystectomy, with good operative view, good ergonomy and should bear in mind the risk of this injury especially if fatigued. Both procedures can be accompanied by intraoperative incidents and accidents, which can lead to severe morbidity. If a postcholecystectomy syndrome is suspected in the postoperative period, a careful evaluation of the patient must also include suspicion of hiatal hernia recurrence. In conclusion, concomitant laparoscopic hiatal hernia repair and cholecystectomy is a safe and feasible option for patients with indication of surgery for both pathologies.

\section{Declarations}

\section{Ethics approval and consent to participate}

We have the acquired approval by our investigational review board

\section{Consent for publication}

We have the acquired approval by our investigational review board

\section{Availability of data and material}

We have the necessary material available to whom may concern

\section{Competing interests}

None to declare

\section{Funding}

None to declare

\section{Authors' contributions}

All authors contributed equally

\section{Acknowledgements}

None to declare

\section{References}

1. Yang X, Hua R, He K, Shen Q, Yao Q. Laparoscopic hernioplasty of hiatal hernia. Annals of translational medicine. 2016;4(18):343.

2. Kohn GP, Price RR, DeMeester SR, Zehetner J, Muensterer OJ, Awad Z, Mittal SK, Richardson WS, Stefanidis D, Fanelli RD, et al. Guidelines for the management of hiatal hernia. Surgical endoscopy. 
2013;27(12):4409-28.

3. Soper NJ, Stockmann PT, Dunnegan DL, Ashley SW. Laparoscopic cholecystectomy. The new 'gold standard'? Archives of surgery. 1992;127(8):917-21. discussion 921 - 913.

4. Wadhwa A, Chowbey PK, Sharma A, Khullar R, Soni V, Baijal M. Combined procedures in laparoscopic surgery. Surg Laparosc Endosc Percutan Tech. 2003;13(6):382-6.

5. Sasaki A, Nitta H, Otuska K, Kimura Y, Obuchi T, Wakabayashi G. Concomitant laparoscopic splenectomy and cholecystectomy. Surg Laparosc Endosc Percutan Tech. 2010;20(2):66-8.

6. Savita K, Khedkar I, Bhartia VK. Combined procedures with laparoscopic cholecystectomy. The Indian journal of surgery. 2010;72(5):377-80.

7. Clapp B. Optimal Initial Trocar Placement for Morbidly Obese Patients. JSLS: Journal of the Society of Laparoendoscopic Surgeons 2018, 22(4).

8. Preda SD, Patrascu S, Ungureanu BS, Cristian D, Bintintan V, Nica CM, Calu V, Strambu V, Sapalidis K, Surlin VM. Primary parahiatal hernias: A case report and review of the literature. World journal of clinical cases. 2019;7(23):4020-8.

9. Praveen Raj P, Senthilnathan P, Kumaravel R, Rajpandian S, Rajan PS, Anand Vijay N, Palanivelu C. Concomitant laparoscopic ventral hernia mesh repair and bariatric surgery: a retrospective study from a tertiary care center. Obes Surg. 2012;22(5):685-9.

10. Birolini C, Utiyama EM, Rodrigues AJ Jr, Birolini D. Elective colonic operation and prosthetic repair of incisional hernia: does contamination contraindicate abdominal wall prosthesis use? J Am Coll Surg. 2000;191(4):366-72.

11. De Biasi A, Lumpkins K, Turner PL. Laparoscopic ventral hernia repair with acute perforated cholecystitis and no short- or long-term evidence of prosthesis infection. Am Surg. 2011;77(4):5101 .

12. Stringer RA, Salameh JR. Mesh herniorrhaphy during elective colorectal surgery. Hernia: the journal of hernias abdominal wall surgery. 2005;9(1):26-8.

13. Simon E, Kelemen O, Knausz J, Bodnar S, Batorfi J. Synchronically performed laparoscopic cholecystectomy and hernioplasty. Acta Chir Hung. 1999;38(2):205-7.

14. Kelly ME, Behrman SW. The safety and efficacy of prosthetic hernia repair in clean-contaminated and contaminated wounds. Am Surg. 2002;68(6):524-8. discussion 528-529.

15. Albasini JL, Aledo VS, Dexter SP, Marton J, Martin IG, McMahon MJ. Bile leakage following laparoscopic cholecystectomy. Surgical endoscopy. 1995;9(12):1274-8.

16. Bailey RW, Zucker KA, Flowers JL, Scovill WA, Graham SM, Imbembo AL. Laparoscopic cholecystectomy. Experience with 375 consecutive patients. Annals of surgery. 1991;214(4):531-40. discussion 540 - 531 .

17. Singal R, Sharma A, Zaman M. The Safety and Efficacy of Clipless versus Conventional Laparoscopic Cholecystectomy - our Experience in an Indian Rural Center. Maedica. 2018;13(1):3443. 
18. Flum DR, Cheadle A, Prela C, Dellinger EP, Chan L. Bile duct injury during cholecystectomy and survival in medicare beneficiaries. Jama. 2003;290(16):2168-73.

19. Gouma DJ, Go PM. Bile duct injury during laparoscopic and conventional cholecystectomy. J Am Coll Surg. 1994;178(3):229-33.

20. Roslyn JJ, Binns GS, Hughes EF, Saunders-Kirkwood K, Zinner MJ, Cates JA. Open cholecystectomy. A contemporary analysis of 42,474 patients. Annals of surgery. 1993;218(2):129-37.

\section{Figures}

\section{Case distribution by age group}

14

12

11

9

7

5

4

2

0

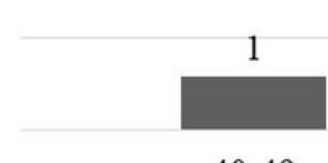

40-49
2

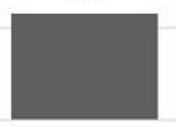

50-59
13

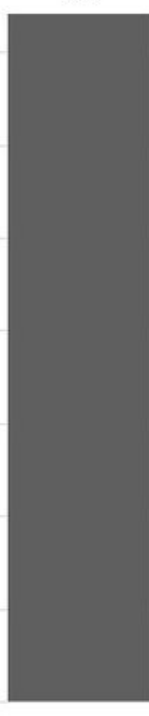

$60-69$
4

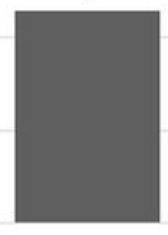

70-79

Figure 1 


\section{Cholecystitis}

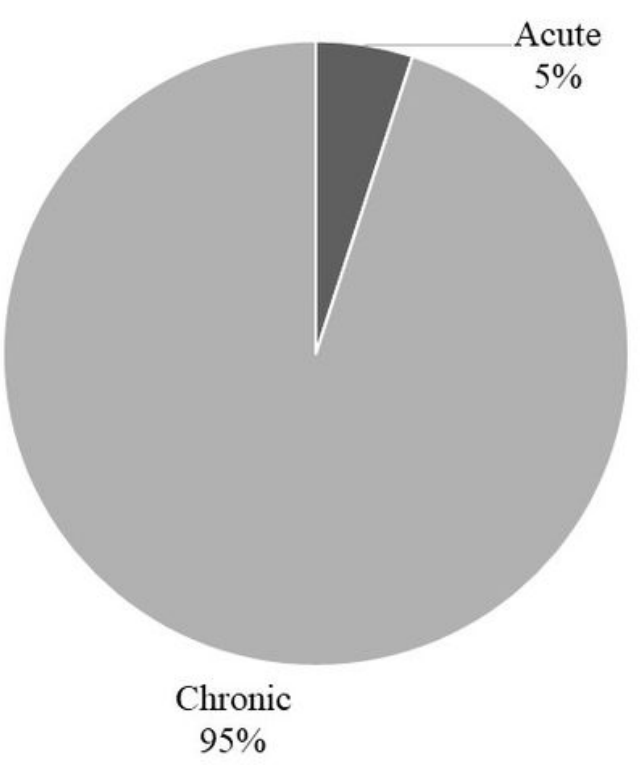

\section{Figure 2}

Type IV $30 \%$

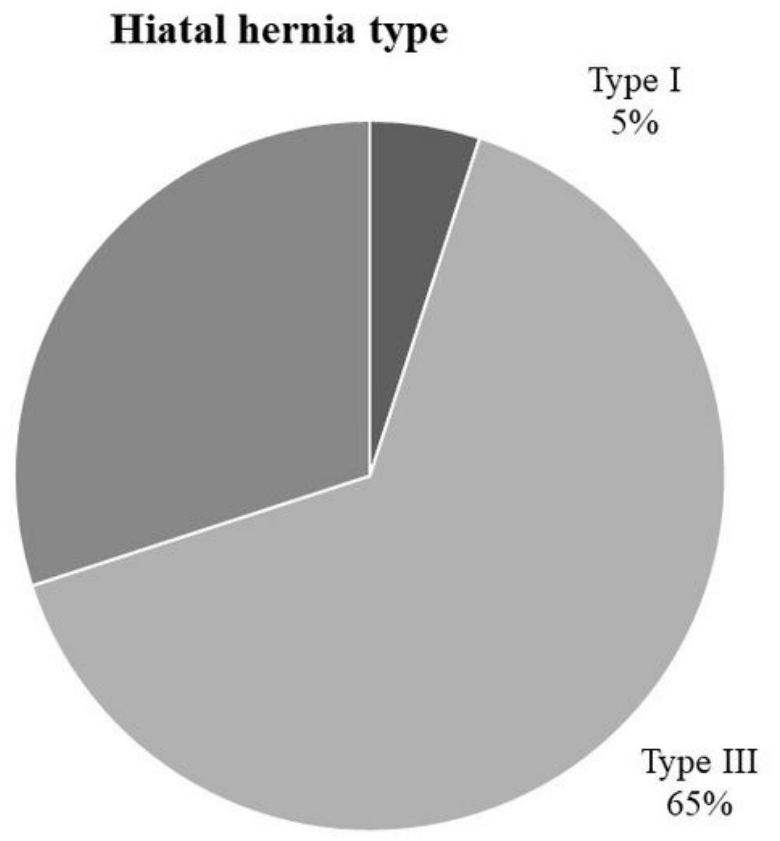

- Type I - Type III

घ Type IV

Figure 3 


\section{Presenting symptoms}

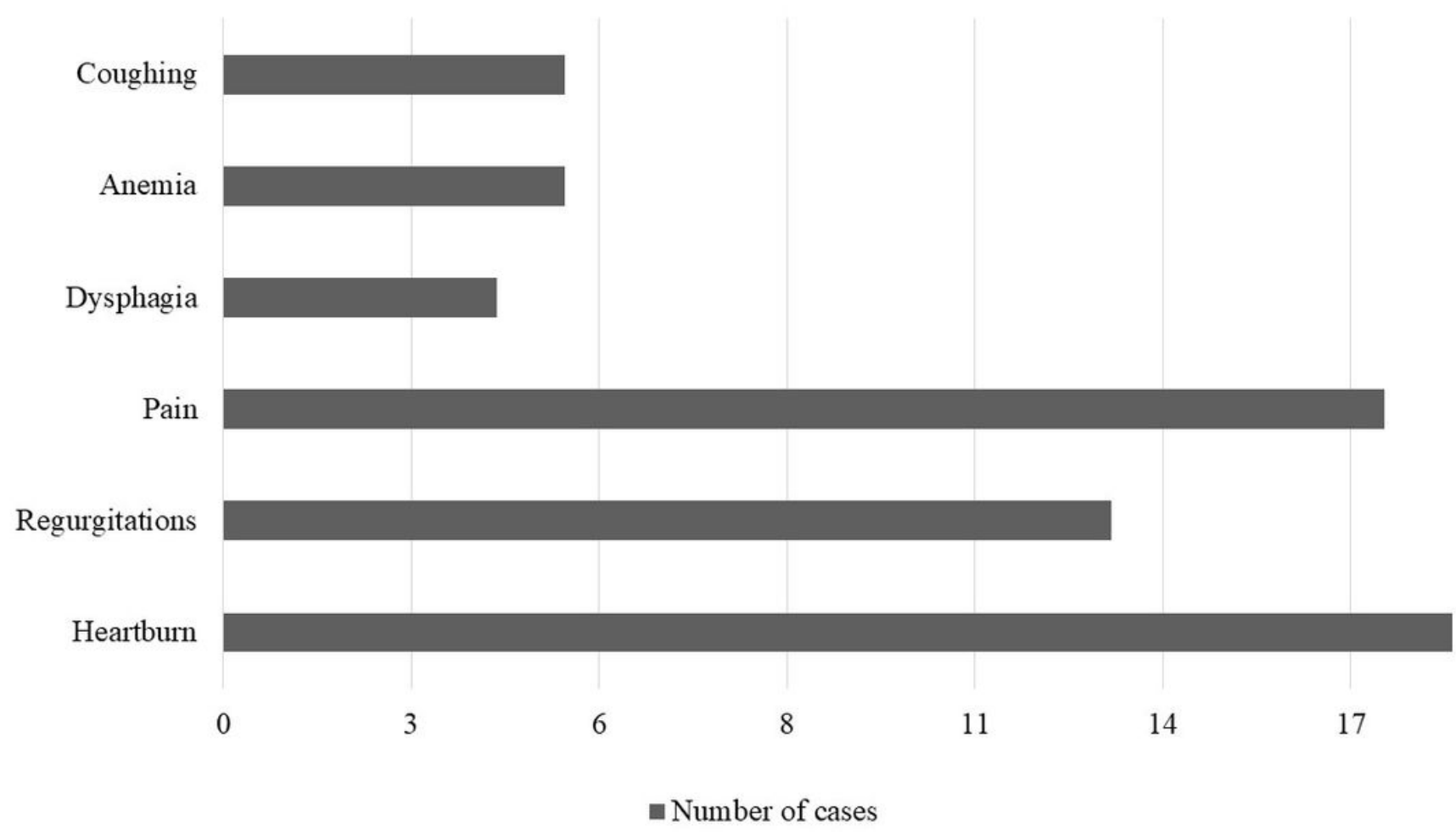

\section{Figure 4}

\section{Performed imaging}

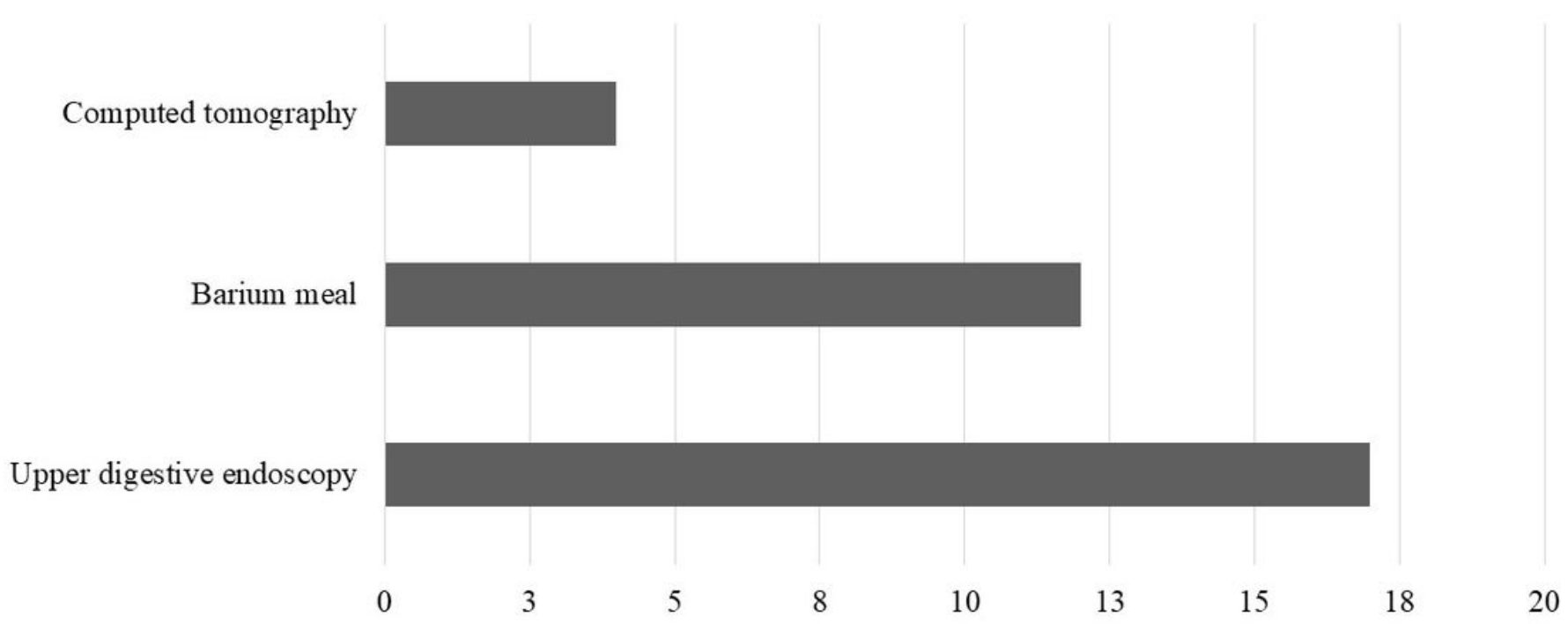

number of cases

Figure 5 


\section{Visual Analog Scale}

12

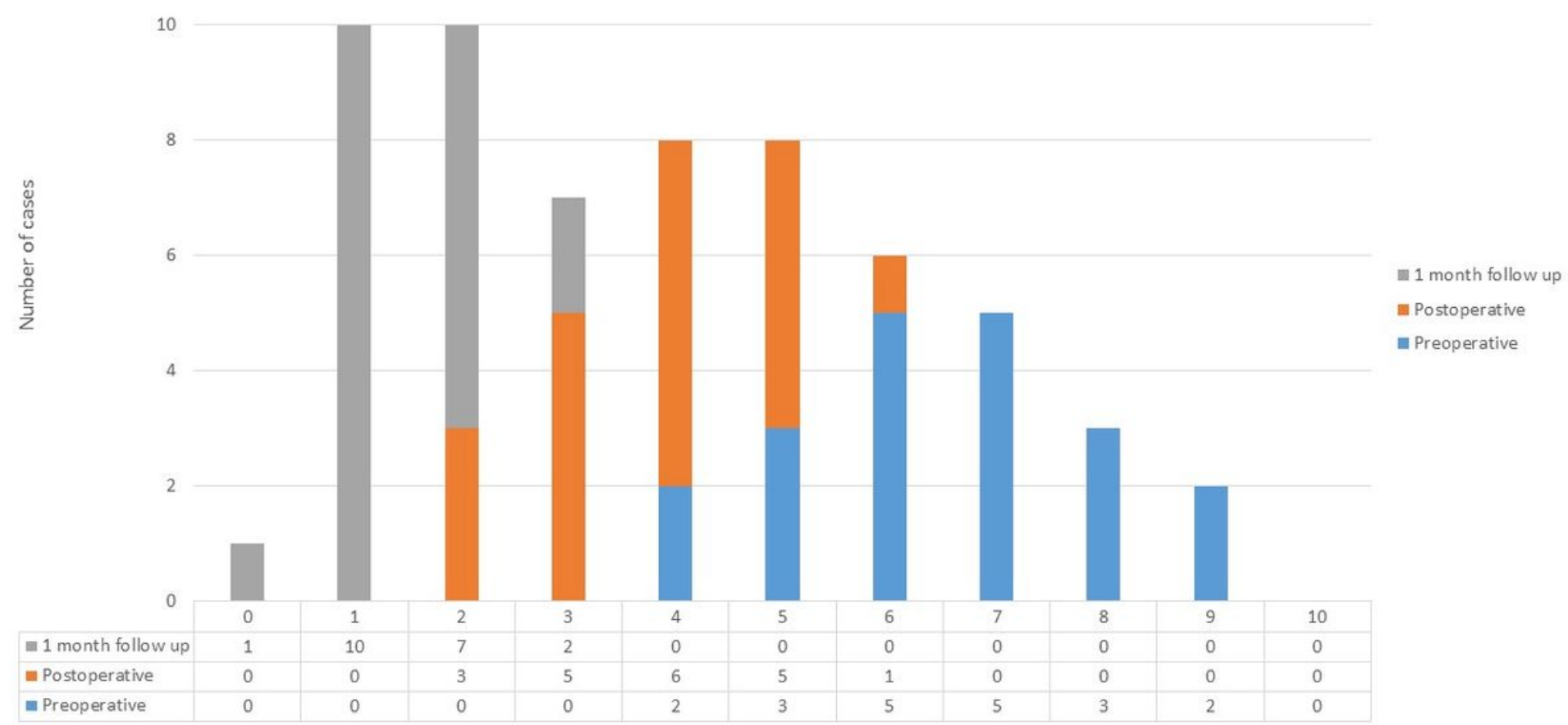

Figure 6 